\title{
A Single-Sample Estimate of Shrinkage in Meteorological Forecasting
}

\author{
Paul W. Mielke JR. \\ Department of Statistics, Colorado State University, Fort Collins, Colorado \\ KENNETH J. BERRY \\ Department of Sociology, Colorado State University, Fort Collins, Colorado \\ Christopher W. LANDSEA* \\ NOAA Climate and Global Change Fellowship, NOAA/AOML/Hurricane Research Division, Miami, Florida \\ WILLIAM M. GRAY \\ Department of Atmospheric Science, Colorado State University, Fort Collins, Colorado
}

(Manuscript received 20 June 1996, in final form 20 May 1997)

ABSTRACT

\begin{abstract}
An estimator of shrinkage based on information contained in a single sample is presented and the results of a simulation study are reported. The effects of sample size, amount, and severity of nonrepresentative data in the population, inclusion of noninformative predictors, and least (sum of) absolute deviations and least (sum of ) squared deviations regression models are examined on the estimator. A single-sample estimator of shrinkage based on drop-one cross-validation is shown to be highly accurate under a wide variety of research conditions.
\end{abstract}

\section{Introduction}

Meteorologists have long recognized the importance of accurately quantifying statistical forecast skill. One of the primary tools of meteorological forecasting is multiple regression analysis (Murphy and Winkler 1984) where, given data on a response variable $y_{i}$ and associated predictor variables $x_{i j}$, where $j=1, \ldots, p$; $i=1, \ldots, n ; p$ denotes the number of predictors; and $n$ represents the number of events; the goal is to find some function of the $x_{i j}$ values that is an accurate and precise predictor of $y_{i}$. It is generally recognized that any estimate of forecast skill grounded in a multiple regression model that is based on a sample of observations is characteristically higher than the forecast skill that would be obtained from a multiple regression model that is based on the entire population of observations (Mosteller and Tukey 1977; Picard and Cook 1984; Michaelsen 1987; Barnston and Van den Dool 1993). It is

\footnotetext{
* Current affiliation: NOAA/AOML/Hurricane Research Division, Miami, Florida.

Corresponding author address: Dr. Paul W. Mielke Jr., Department of Statistics, Colorado State University, Fort Collins, CO 80523-1877. E-mail: mielke@lamar.colostate.edu
}

also widely accepted that the fit of the multiple regression model to new sample data is nearly always less precise than the fit of the same multiple regression model to the original sample data on which the model was based. This is reflected in lower forecast skill levels obtained when sample-based multiple regression models are used to predict future events.

It is useful to have elementary terms to distinguish between the fit of a multiple regression model to the sample data on which the model has been determined and the fit of the same multiple regression model to an independent sample of data. The former is termed "retrospective" fit and the latter is termed "validation" fit (Copas 1983). The term "shrinkage" denotes the drop in skill from retrospective fit to validation fit (Copas 1983) and indicates how useful the sample-based regression coefficients will be for prediction on other datasets. For purposes of clarification, shrinkage involves the following four-step procedure. First, a multiple regression model is fit to a sample dataset by optimizing the regression coefficients relative to a fitting criterion, for example, least squares. Second, the goodness of fit of the multiple regression model is measured by an index, such as a squared multiple correlation coefficient. Third, the obtained multiple regression model is applied to an independent sample dataset and a second goodness-of-fit index is obtained for the independent dataset. 
Fourth, a ratio of the two indices is constructed where the goodness-of-fit index from the original dataset is the denominator. This ratio is termed shrinkage since it is usually less than unity.

Mielke et al. (1996) investigated the effects of sample size, type of regression model, and noise-to-signal ratio on the degree of shrinkage in five populations that differed in the amount and degree of contaminated data. Shrinkage was defined as the ratio of the validation fit of a sample regression equation to the retrospective fit of the same sample regression equation where the validation fit was assessed on five independent samples, averaged over 10000 simulations. While this index of shrinkage is both rigorous and comprehensive, the use of six independent samples precludes its use in routine research situations. In this paper, an estimate of shrinkage is developed that is based on a single sample and can easily be employed by research meteorologists. Comparisons with the index of shrinkage given by Mielke et al. (1996) indicate that the single-sample estimate of shrinkage is very accurate under a wide variety of conditions. The single-sample estimate of shrinkage is related to cross-validation methods that have become standard for assessing the predictive validity of forecast skill.

\section{Cross-validation}

Historically, users of multiple regression procedures have developed methods to assess how accurately sample regression coefficients estimate the corresponding population regression coefficients. The usual procedure is to test the sample regression coefficients on an independent set of sample data. This practice has come to be known as "cross-validation." A comprehensive historical background on cross-validation is provided by Stone (1974, 1978), Geisser (1975), Mosteller and Tukey (1977), and Snee (1977). Camstra and Boomsma (1992) present an extensive overview of the use of cross-validation in regression, where the emphasis is on the prediction of individual observations, and in covariance structure analysis, where the emphasis is on future values of variances and covariances. Michaelsen (1987) and Elsner and Schmertmann (1994) describe and discuss cross-validation methods as they pertain to meteorological forecasting.

It is widely recognized that to be useful, any sample regression equation must hold for data other than those on which the regression equation was developed. When sample data are used to determine the regression coefficients that best predict the response variable from the set of predictor variables, assuming that the variables to be used in the regression equation have already been selected, prediction performance is usually overestimated (Picard and Cook 1984). Because the sample regression coefficients are determined by an optimizing process that is conditioned on the sample data, the regression equation generally provides better predictions for the sample data on which it is based than for any other dataset. This is sometimes referred to as "testing on the training data" (Glick 1978). It should be noted that the use of cross-validation precludes any manipulation of the dataset prior to the development of the regression model and subsequent cross-validation.

In general, cross-validation consists of determining the regression coefficients in one sample and applying the obtained coefficients to the predictor scores of another sample. The initial sample is termed the "calibration" or "training" sample and the second sample is called the "validation" or "test" sample (Browne 1975a,b; Huberty et al. 1987; Camstra and Boomsma 1992; MacCallum et al. 1994). The calibration sample is used to calculate the regression coefficients, and the predictive validity of the fitted equation is verified on the validation sample.

As defined, cross-validation requires two samples. Because a second sample is often not readily available, an alternative approach is often used in which a large sample is randomly split into two subsamples. One subsample is specified as the calibration sample and the second sample is designated the validation sample. The many problems associated with this approach to crossvalidation are summarized in Lachenbruch and Mickey (1968), Picard and Cook (1984), and Picard and Berk (1990). Setting aside the obvious loss of information in splitting samples (Browne and Cudeck 1992), a significant problem is the difficulty in procuring large samples, which are not available in many research situations. In addition, when calibration sample sizes are small, the regression coefficients are less precise than those that would be obtained if the entire sample had been used (Horst 1966). Mosier (1951) suggested a double cross-validation procedure where the regression coefficients are calculated for both the calibration and validation samples and the two regression equations are cross-validated on the sample that was not used to establish the regression coefficients. Questions have been raised as to exactly what should be done when the results of the two cross-validations differ (Snee 1977). It has been suggested that if the two sets of regression coefficients are not too different, then a new set of coefficients may be obtained from the combined calibration and validation samples (Mosier 1951). While no estimate of predictive validity is available for the combined sample, Mosier (1951) posited that it may be approximated by the average of the predictive validities obtained for the original calibration and validation samples.

Cross-validation is certainly not limited to just two samples. The data can be divided into more than two samples and multiple cross-validations can be obtained. Multiple cross-validation involves partitioning an available sample of size $n$ into a calibration sample of size $n-k$ and a validation sample of size $k$. The crossvalidation procedure is realized by withholding each validation sample of size $k$, calculating a regression 
TABLE 1. Population 1: Initial population consisting of 3958 noncontaminated events. Columns are (C1) true population $\rho$ values (C2) average of 10000 sample $\hat{\rho}$ values based on regression coefficients for each sample, (C3) average of five sample $\hat{\rho}$ values for each of 10 000 random sets of regression coefficients associated with the 10000 samples of C2, (C4) average of 10000 drop-one $\hat{\rho}$ values estimated for each of the 10000 samples of $\mathrm{C} 2$, and corresponding ratios $(\mathrm{C} 3 / \mathrm{C} 2),(\mathrm{C} 4 / \mathrm{C} 2),(\mathrm{C} 4 / \mathrm{C} 3)$, and $(\mathrm{C} 3 / \mathrm{C} 1)$.

\begin{tabular}{|c|c|c|c|c|c|c|c|c|c|c|}
\hline $\begin{array}{c}\text { Sample } \\
\text { size }\end{array}$ & Case & Model & $\mathrm{C} 1$ & $\mathrm{C} 2$ & $\mathrm{C} 3$ & $\mathrm{C} 4$ & $\mathrm{C} 3 / \mathrm{C} 2$ & $\mathrm{C} 4 / \mathrm{C} 2$ & $\mathrm{C} 4 / \mathrm{C} 3$ & $\mathrm{C} 3 / \mathrm{C} 1$ \\
\hline \multirow[t]{4}{*}{15} & 10 & LAD & 0.51495 & 0.83216 & 0.21959 & 0.19520 & 0.264 & 0.235 & 0.889 & 0.426 \\
\hline & & LSD & 0.51154 & 0.76579 & 0.24721 & 0.20980 & 0.323 & 0.277 & 0.849 & 0.483 \\
\hline & 6 & LAD & 0.51130 & 0.69947 & 0.32214 & 0.29055 & 0.461 & 0.415 & 0.902 & 0.630 \\
\hline & & LSD & 0.50917 & 0.64059 & 0.34883 & 0.31267 & 0.545 & 0.488 & 0.896 & 0.685 \\
\hline \multirow[t]{4}{*}{25} & 10 & LAD & 0.51495 & 0.69659 & 0.34693 & 0.33158 & 0.498 & 0.476 & 0.956 & 0.674 \\
\hline & & LSD & 0.51154 & 0.63931 & 0.37427 & 0.35416 & 0.585 & 0.554 & 0.946 & 0.732 \\
\hline & 6 & LAD & 0.51130 & 0.61963 & 0.39741 & 0.37757 & 0.641 & 0.609 & 0.950 & 0.777 \\
\hline & & LSD & 0.50917 & 0.57839 & 0.41795 & 0.39942 & 0.723 & 0.691 & 0.956 & 0.821 \\
\hline \multirow[t]{4}{*}{40} & 10 & LAD & 0.51495 & 0.62613 & 0.41279 & 0.40342 & 0.659 & 0.644 & 0.977 & 0.802 \\
\hline & & LSD & 0.51154 & 0.58533 & 0.43132 & 0.42250 & 0.737 & 0.722 & 0.980 & 0.843 \\
\hline & 6 & LAD & 0.51130 & 0.57687 & 0.43965 & 0.42829 & 0.762 & 0.742 & 0.974 & 0.860 \\
\hline & & LSD & 0.50917 & 0.54955 & 0.45455 & 0.44493 & 0.827 & 0.810 & 0.988 & 0.893 \\
\hline \multirow[t]{4}{*}{65} & 10 & LAD & 0.51495 & 0.58265 & 0.45361 & 0.44876 & 0.779 & 0.770 & 0.989 & 0.881 \\
\hline & & LSD & 0.51154 & 0.55438 & 0.46425 & 0.45954 & 0.837 & 0.829 & 0.990 & 0.908 \\
\hline & 6 & LAD & 0.51130 & 0.55102 & 0.46701 & 0.46115 & 0.848 & 0.837 & 0.987 & 0.913 \\
\hline & & LSD & 0.50917 & 0.53274 & 0.47611 & 0.47099 & 0.894 & 0.884 & 0.989 & 0.935 \\
\hline \multirow{4}{*}{100} & 10 & LAD & 0.51495 & 0.55843 & 0.47627 & 0.47168 & 0.853 & 0.845 & 0.990 & 0.925 \\
\hline & & LSD & 0.51154 & 0.53790 & 0.48182 & 0.47803 & 0.896 & 0.889 & 0.992 & 0.942 \\
\hline & 6 & LAD & 0.51130 & 0.53651 & 0.48269 & 0.47818 & 0.900 & 0.891 & 0.991 & 0.944 \\
\hline & & LSD & 0.50917 & 0.52353 & 0.48814 & 0.48429 & 0.932 & 0.925 & 0.992 & 0.959 \\
\hline \multirow[t]{4}{*}{160} & 10 & LAD & 0.51495 & 0.54290 & 0.49184 & 0.48998 & 0.906 & 0.903 & 0.996 & 0.955 \\
\hline & & LSD & 0.51154 & 0.52759 & 0.49302 & 0.49183 & 0.934 & 0.932 & 0.998 & 0.965 \\
\hline & 6 & LAD & 0.51130 & 0.52727 & 0.49364 & 0.49187 & 0.936 & 0.933 & 0.996 & 0.965 \\
\hline & & LSD & 0.50917 & 0.51780 & 0.49598 & 0.49463 & 0.958 & 0.955 & 0.997 & 0.974 \\
\hline \multirow[t]{4}{*}{250} & 10 & LAD & 0.51495 & 0.53325 & 0.50076 & 0.50011 & 0.939 & 0.938 & 0.999 & 0.972 \\
\hline & & LSD & 0.51154 & 0.52141 & 0.49982 & 0.49965 & 0.959 & 0.958 & 1.000 & 0.977 \\
\hline & 6 & LAD & 0.51130 & 0.52160 & 0.50012 & 0.50004 & 0.959 & 0.959 & 1.000 & 0.978 \\
\hline & & LSD & 0.50917 & 0.51454 & 0.50081 & 0.50080 & 0.973 & 0.973 & 1.000 & 0.984 \\
\hline \multirow[t]{4}{*}{500} & 10 & LAD & 0.51495 & 0.52527 & 0.50865 & 0.50660 & 0.968 & 0.964 & 0.996 & 0.988 \\
\hline & & LSD & 0.51154 & 0.51661 & 0.50562 & 0.50355 & 0.985 & 0.975 & 0.996 & 0.988 \\
\hline & 6 & LAD & 0.51130 & 0.51685 & 0.50578 & 0.50422 & 0.979 & 0.976 & 0.997 & 0.989 \\
\hline & & LSD & 0.50917 & 0.51206 & 0.50500 & 0.50294 & 0.986 & 0.982 & 0.991 & 0.992 \\
\hline
\end{tabular}

model from the remaining calibration sample of size $n$ $-k$, and validating each of the $\left(\begin{array}{l}n \\ k\end{array}\right)$ possible regression models on the remaining sample of size $k$ held in reserve. Since $k=1$ requires validating only $n$ regression models on the remaining sample of size 1 held in reserve, this special case is both easily implemented and commonly used. In various literature, the case where $k$ $=1$ is termed drop-one cross-validation, leave-one-out cross-validation, hold-one-out cross-validation, or the $U$ method. Stone (1978) provides a thorough review of drop-one cross-validation. Drop-one cross-validation is an exhaustive method involving substantial redundancy in the participation of each data point (far more redundancy when $k>1$ ). However, the exhaustive features of drop-one cross-validation may provide a comprehensive evaluation of predictive accuracy and a solid estimate of predictive skill (Barnston and Van den Dool 1993).

Drop-one cross-validation is usually credited to Lachenbruch (1967) or Lachenbruch and Mickey (1968). However, Toussaint (1974) has traced the drop-one method to earlier sources under different names (Glick 1978). Currently, the drop-one method is the cross-validation procedure of choice and it is not unusual to see the term cross-validation virtually equated with the drop-one method (e.g., Nicholls 1985; Livezey et al. 1990).

For many researchers, the method of choice for crossvalidation is to create a model on one sample and test the model on a second sample drawn from the same population; alternatively, a model is created on a substantial portion of a sample and tested on the remaining portion of the sample. In either case, the selection of predictors can be based on information in the population or some other out-of-sample source, or the selection of predictors can involve subset selection based on in-sample information. In addition, the regression coefficients are nearly always based on information in the calibration sample. Much of the early work in cross-validation specifically limited analyses to fixed models where the number and variety of predictors is determined a priori and not based on subset selection (e.g., Browne 1975a, 1975b; Camstra and Boomsma 1992; MacCallum et al. 1994). Thus, cross-validation in this context implies validation of the sample regression coefficients only. In those cases where subset selection is based on the sample information, cross-validation implies validation of 
TABLE 2. Population 2: Contaminated population consisting of 3998 events consisting of the initial population of 3958 events and 40 moderately extreme events. Columns are (C1) true population $\rho$ values, (C2) average of 10000 sample $\hat{\rho}$ values based on regression coefficients for each sample, (C3) average of five sample $\hat{\rho}$ values for each of 10000 random sets of regression coefficients associated with the 10000 samples of $\mathrm{C} 2$, (C4) average of 10000 drop-one $\hat{\rho}$ values estimated for each of the 10000 samples of $\mathrm{C} 2$, and corresponding ratios $(\mathrm{C} 3 / \mathrm{C} 2),(\mathrm{C} 4 / \mathrm{C} 2),(\mathrm{C} 4 / \mathrm{C} 3)$, and $(\mathrm{C} 3 / \mathrm{C} 1)$.

\begin{tabular}{|c|c|c|c|c|c|c|c|c|c|c|}
\hline $\begin{array}{l}\text { Sample } \\
\text { size }\end{array}$ & Case & Model & $\mathrm{C} 1$ & $\mathrm{C} 2$ & C3 & $\mathrm{C} 4$ & $\mathrm{C} 3 / \mathrm{C} 2$ & $\mathrm{C} 4 / \mathrm{C} 2$ & $\mathrm{C} 4 / \mathrm{C} 3$ & $\mathrm{C} 3 / \mathrm{C} 1$ \\
\hline \multirow[t]{4}{*}{15} & 10 & LAD & 0.48886 & 0.83077 & 0.20662 & 0.18590 & 0.249 & 0.224 & 0.900 & 0.423 \\
\hline & & LSD & 0.45120 & 0.76387 & 0.23315 & 0.20030 & 0.305 & 0.262 & 0.859 & 0.517 \\
\hline & 6 & LAD & 0.48220 & 0.69081 & 0.30215 & 0.28085 & 0.437 & 0.407 & 0.930 & 0.627 \\
\hline & & LSD & 0.44984 & 0.63008 & 0.32887 & 0.29919 & 0.522 & 0.475 & 0.910 & 0.731 \\
\hline \multirow[t]{4}{*}{25} & 10 & LAD & 0.48886 & 0.69099 & 0.32943 & 0.31682 & 0.477 & 0.459 & 0.962 & 0.674 \\
\hline & & LSD & 0.45120 & 0.63311 & 0.35703 & 0.33872 & 0.564 & 0.535 & 0.949 & 0.791 \\
\hline & 6 & LAD & 0.48220 & 0.60467 & 0.37074 & 0.35322 & 0.613 & 0.584 & 0.953 & 0.769 \\
\hline & & LSD & 0.44984 & 0.56220 & 0.39249 & 0.37486 & 0.698 & 0.667 & 0.955 & 0.873 \\
\hline \multirow[t]{4}{*}{40} & 10 & LAD & 0.48886 & 0.61657 & 0.38947 & 0.38038 & 0.632 & 0.617 & 0.977 & 0.797 \\
\hline & & LSD & 0.45120 & 0.57548 & 0.40904 & 0.39914 & 0.711 & 0.694 & 0.976 & 0.907 \\
\hline & 6 & LAD & 0.48220 & 0.55632 & 0.40805 & 0.39739 & 0.733 & 0.714 & 0.974 & 0.846 \\
\hline & & LSD & 0.44984 & 0.52658 & 0.42208 & 0.41204 & 0.802 & 0.782 & 0.976 & 0.938 \\
\hline \multirow[t]{4}{*}{65} & 10 & LAD & 0.48886 & 0.56622 & 0.42434 & 0.41918 & 0.749 & 0.740 & 0.988 & 0.868 \\
\hline & & LSD & 0.45120 & 0.53715 & 0.43587 & 0.43264 & 0.811 & 0.805 & 0.993 & 0.966 \\
\hline & 6 & LAD & 0.48220 & 0.52586 & 0.43418 & 0.42843 & 0.826 & 0.815 & 0.987 & 0.900 \\
\hline & & LSD & 0.44984 & 0.50036 & 0.43615 & 0.43242 & 0.872 & 0.864 & 0.991 & 0.970 \\
\hline \multirow[t]{4}{*}{100} & 10 & LAD & 0.48886 & 0.53914 & 0.44413 & 0.43980 & 0.824 & 0.816 & 0.990 & 0.909 \\
\hline & & LSD & 0.45120 & 0.51555 & 0.44819 & 0.44515 & 0.869 & 0.863 & 0.993 & 0.993 \\
\hline & 6 & LAD & 0.48220 & 0.51103 & 0.45081 & 0.44633 & 0.882 & 0.873 & 0.990 & 0.935 \\
\hline & & LSD & 0.44984 & 0.48556 & 0.44265 & 0.43940 & 0.912 & 0.905 & 0.993 & 0.984 \\
\hline \multirow[t]{4}{*}{160} & 10 & LAD & 0.48886 & 0.51867 & 0.45922 & 0.45747 & 0.885 & 0.882 & 0.996 & 0.939 \\
\hline & & LSD & 0.45120 & 0.49590 & 0.45266 & 0.45185 & 0.913 & 0.911 & 0.998 & 1.003 \\
\hline & 6 & LAD & 0.48220 & 0.49982 & 0.46294 & 0.46082 & 0.926 & 0.922 & 0.995 & 0.960 \\
\hline & & LSD & 0.44984 & 0.47246 & 0.44554 & 0.44477 & 0.943 & 0.941 & 0.998 & 0.990 \\
\hline \multirow[t]{4}{*}{250} & 10 & LAD & 0.48886 & 0.50767 & 0.46914 & 0.46727 & 0.924 & 0.920 & 0.996 & 0.960 \\
\hline & & LSD & 0.45120 & 0.48257 & 0.45410 & 0.45271 & 0.941 & 0.938 & 0.997 & 1.006 \\
\hline & 6 & LAD & 0.48220 & 0.49408 & 0.47041 & 0.46900 & 0.952 & 0.949 & 0.997 & 0.964 \\
\hline & & LSD & 0.44984 & 0.46486 & 0.44727 & 0.44579 & 0.962 & 0.959 & 0.997 & 0.994 \\
\hline \multirow[t]{4}{*}{500} & 10 & LAD & 0.48886 & 0.49896 & 0.47922 & 0.47885 & 0.960 & 0.960 & 0.999 & 0.980 \\
\hline & & LSD & 0.45120 & 0.46904 & 0.45367 & 0.45338 & 0.967 & 0.967 & 0.999 & 1.005 \\
\hline & 6 & LAD & 0.48220 & 0.48999 & 0.47780 & 0.47740 & 0.975 & 0.974 & 0.999 & 0.991 \\
\hline & & LSD & 0.44984 & 0.45838 & 0.44897 & 0.44878 & 0.979 & 0.979 & 1.000 & 0.998 \\
\hline
\end{tabular}

the subset selection process and the sample regression coefficients.

The advent of double cross-validation brought additional complications. Given fixed predictors, the regression coefficients from each sample are tested on the other sample and any differences can be consolidated by some form of weighted averaging of the regression coefficients (Subrahmanyam 1972). However, given sample-based subset selection, there is the added complication that each sample will select a different number and/or a different set of predictors. It is much more difficult to resolve discrepancies between the two sample validation results. Browne (1970) provides results of random sampling experiments demonstrating the effects of not fixing the predictors beforehand. With dropone cross-validation it is possible to conceive of up to $n$ different but overlapping sets of predictors and up to $n$ different values for the regression coefficients for each predictor. The satisfactory and optimal combining of these differences appears very difficult; see, for example, Browne and Cudeck (1989) and MacCallum et al. (1994).

Cross-validation is not without its critics and there is evidence that suggests some possible drawbacks to drop-one cross-validation. Glick (1978) and Hora and Wilcox (1982) provide simulation studies of drop-one cross-validation in discriminant analysis. Both studies indicate that the estimates have relatively high variability over repeated sampling, possibly due to the repeated use of the original data. The results of both Glick (1978) and Hora and Wilcox (1982) were based on discriminant analysis, which has a binary error function. Efron (1983) notes that cross-validation performs somewhat better given a smooth residual sum of squares error function. Finally, some investigators note that a model that fits the validation sample as well as the calibration sample is not necessarily a validated model. Maltz (1994), for example, argues that cross-validation may only show that the procedure used to split the sample did, in fact, divide the sample into two similar subgroups.

If a specific sample dataset exhibits a high first-order autoregressive pattern, drop-one cross-validation may overestimate the validation fit. For example, if a single sample consists of cases selected from a time series, then the cases in a given cycle (e.g., a month, a year, 
TABle 3. Population 3: Contaminated population of 3998 events of the initial population of 3958 events and 40 very extreme events. Columns are (C1) true population $\rho$ values, (C2) average of 10000 sample $\hat{\rho}$ values based on regression coefficients for each sample, (C3) average of five sample $\hat{\rho}$ values for each of 10000 random sets of regression coefficients associated with the 10000 samples of C2, (C4) average of 10000 drop-one $\hat{\rho}$ values estimated for each of the 10000 samples of $\mathrm{C} 2$, and corresponding ratios (C3/C2), (C4/C2), (C4/C3), and $(\mathrm{C} 3 / \mathrm{C} 1)$.

\begin{tabular}{|c|c|c|c|c|c|c|c|c|c|c|}
\hline $\begin{array}{l}\text { Sample } \\
\text { size }\end{array}$ & Case & Model & $\mathrm{C} 1$ & $\mathrm{C} 2$ & $\mathrm{C} 3$ & $\mathrm{C} 4$ & $\mathrm{C} 3 / \mathrm{C} 2$ & $\mathrm{C} 4 / \mathrm{C} 2$ & $\mathrm{C} 4 / \mathrm{C} 3$ & $\mathrm{C} 3 / \mathrm{C} 1$ \\
\hline \multirow[t]{4}{*}{15} & \multirow[t]{2}{*}{10} & LAD & 0.44873 & 0.83121 & 0.20082 & 0.18153 & 0.242 & 0.218 & 0.904 & 0.448 \\
\hline & & LSD & 0.29776 & 0.76468 & 0.22665 & 0.19527 & 0.296 & 0.255 & 0.862 & 0.761 \\
\hline & \multirow[t]{2}{*}{6} & LAD & 0.43722 & 0.69002 & 0.29357 & 0.27530 & 0.425 & 0.399 & 0.938 & 0.671 \\
\hline & & LSD & 0.27225 & 0.62930 & 0.31866 & 0.29310 & 0.506 & 0.466 & 0.920 & 1.170 \\
\hline \multirow[t]{4}{*}{25} & \multirow[t]{2}{*}{10} & LAD & 0.44873 & 0.69172 & 0.31845 & 0.30758 & 0.460 & 0.445 & 0.966 & 0.710 \\
\hline & & LSD & 0.29776 & 0.63445 & 0.34486 & 0.32807 & 0.544 & 0.517 & 0.951 & 1.158 \\
\hline & \multirow[t]{2}{*}{6} & LAD & 0.43722 & 0.60065 & 0.35366 & 0.34098 & 0.589 & 0.568 & 0.964 & 0.809 \\
\hline & & LSD & 0.27225 & 0.55827 & 0.37435 & 0.36124 & 0.671 & 0.647 & 0.965 & 1.375 \\
\hline \multirow[t]{4}{*}{40} & \multirow[t]{2}{*}{10} & LAD & 0.44873 & 0.61802 & 0.37532 & 0.36669 & 0.607 & 0.593 & 0.977 & 0.836 \\
\hline & & LSD & 0.29776 & 0.57769 & 0.39366 & 0.38507 & 0.681 & 0.667 & 0.978 & 1.322 \\
\hline & \multirow[t]{2}{*}{6} & LAD & 0.43722 & 0.54451 & 0.37879 & 0.37480 & 0.696 & 0.688 & 0.989 & 0.866 \\
\hline & & LSD & 0.27225 & 0.51698 & 0.39520 & 0.39098 & 0.764 & 0.756 & 0.989 & 1.452 \\
\hline \multirow[t]{4}{*}{65} & \multirow[t]{2}{*}{10} & LAD & 0.44873 & 0.56667 & 0.40517 & 0.40388 & 0.715 & 0.713 & 0.997 & 0.903 \\
\hline & & LSD & 0.29776 & 0.53918 & 0.41701 & 0.41612 & 0.773 & 0.772 & 0.998 & 1.400 \\
\hline & \multirow[t]{2}{*}{6} & LAD & 0.43722 & 0.49965 & 0.38841 & 0.38981 & 0.777 & 0.780 & 1.004 & 0.888 \\
\hline & & LSD & 0.27225 & 0.47894 & 0.39580 & 0.39865 & 0.826 & 0.832 & 1.007 & 1.454 \\
\hline \multirow[t]{4}{*}{100} & \multirow[t]{2}{*}{10} & LAD & 0.44873 & 0.53523 & 0.41757 & 0.41608 & 0.780 & 0.777 & 0.996 & 0.931 \\
\hline & & LSD & 0.29776 & 0.51541 & 0.42518 & 0.42465 & 0.825 & 0.824 & 0.999 & 1.428 \\
\hline & \multirow[t]{2}{*}{6} & LAD & 0.43722 & 0.47492 & 0.39691 & 0.39539 & 0.836 & 0.833 & 0.996 & 0.908 \\
\hline & & LSD & 0.27225 & 0.44794 & 0.38686 & 0.38850 & 0.864 & 0.867 & 1.004 & 1.421 \\
\hline \multirow[t]{4}{*}{160} & \multirow[t]{2}{*}{10} & LAD & 0.44873 & 0.50458 & 0.42088 & 0.42080 & 0.834 & 0.834 & 1.000 & 0.938 \\
\hline & & LSD & 0.29776 & 0.48765 & 0.42113 & 0.42239 & 0.864 & 0.866 & 1.003 & 1.414 \\
\hline & \multirow[t]{2}{*}{6} & LAD & 0.43722 & 0.45708 & 0.40649 & 0.40508 & 0.889 & 0.886 & 0.997 & 0.930 \\
\hline & & LSD & 0.27225 & 0.41056 & 0.36825 & 0.37137 & 0.897 & 0.905 & 1.008 & 1.353 \\
\hline \multirow[t]{4}{*}{250} & \multirow[t]{2}{*}{10} & LAD & 0.44873 & 0.48421 & 0.42473 & 0.42132 & 0.877 & 0.870 & 0.992 & 0.947 \\
\hline & & LSD & 0.29776 & 0.45964 & 0.40951 & 0.40740 & 0.891 & 0.886 & 0.995 & 1.375 \\
\hline & \multirow[t]{2}{*}{6} & LAD & 0.43722 & 0.44837 & 0.41433 & 0.41141 & 0.924 & 0.918 & 0.993 & 0.948 \\
\hline & & LSD & 0.27225 & 0.37856 & 0.34883 & 0.34694 & 0.921 & 0.916 & 0.995 & 1.281 \\
\hline \multirow[t]{4}{*}{500} & \multirow[t]{2}{*}{10} & LAD & 0.44873 & 0.46656 & 0.43340 & 0.43378 & 0.929 & 0.930 & 1.001 & 0.966 \\
\hline & & LSD & 0.29776 & 0.40724 & 0.37716 & 0.37488 & 0.926 & 0.921 & 0.994 & 1.267 \\
\hline & \multirow[t]{2}{*}{6} & LAD & 0.43722 & 0.44242 & 0.42437 & 0.42319 & 0.959 & 0.957 & 0.997 & 0.971 \\
\hline & & LSD & 0.27225 & 0.33445 & 0.31859 & 0.31641 & 0.953 & 0.946 & 0.993 & 1.170 \\
\hline
\end{tabular}

or a decade) may be highly correlated. In such cases a drop- $k$ cross-validation may be required to mitigate the cyclic pattern, where $k$ exceeds the length of the cycle. Michaelsen (1987) has researched the effects of autoregressive effects on cross-validation in statistical climate forecast models.

\section{Statistical measures}

Let the population and sample sizes be denoted by $N$ and $n$, respectively, let $y_{i}$ denote the response variable, and let $x_{i 1}, \ldots, x_{i p}$ denote the $p$ predictor variables associated with the $i$ th of $n$ events. Consider the linear regression model given by

$$
y_{i}=\beta_{0}+\sum_{j=1}^{p} \beta_{j} x_{i j}+e_{i},
$$

where $\beta_{0}, \ldots, \beta_{p}$ are $p+1$ unknown parameters and $e_{i}$ is the error term associated with the $i$ th of $n$ events. Two types of regression models are of interest: least (sum of) absolute deviations (LAD) regression models and least (sum of) squared deviations (LSD) regression models. The LAD and LSD prediction equations are given by

$$
\tilde{y}_{i}=\tilde{\beta}_{0}+\sum_{j=1}^{p} \tilde{\beta}_{j} x_{i j}
$$

where $\tilde{y}_{i}$ is the predicted value of $y_{i}$ and $\tilde{\beta}_{0}, \ldots, \tilde{\beta}_{p}$ minimize the expression

$$
\sum_{i=1}^{n}\left|e_{i}\right|^{v}
$$

with $v=1$ and $v=2$ associated with the LAD and LSD regression models, respectively.

A measure of agreement is employed to determine the correspondence between the $y_{i}$ and $\tilde{y}_{i}$ values, for $i$ $=1, \ldots, n$. Many researchers have utilized measures of agreement in assessing prediction accuracy, for example, Willmott (1982), Willmott et al. (1985), Kelly et al. (1989), Tucker et al. (1989), Gray et al. (1992), McCabe and Legates (1992), Badescu (1993), Elsner and Schmertmann (1993), Hess and Elsner (1994), Cotton et al. (1994), and Lee et al. (1995). Watterson (1996) 
TABle 4. Population 4: Contaminated population of 4158 events of the initial population of 3958 events and 200 moderately extreme events. Columns are (C1) true population $\rho$ values, (C2) average of 10000 sample $\hat{\rho}$ values based on regression coefficients for each sample, (C3) average of five sample $\hat{\rho}$ values for each of 10000 random sets of regression coefficients associated with the 10000 samples of $\mathrm{C} 2$, (C4) average of 10000 drop-one $\hat{\rho}$ values estimated for each of the 10000 samples of $\mathrm{C} 2$, and corresponding ratios (C3/C2), (C4/C2), (C4/ $\mathrm{C} 3)$, and $(\mathrm{C} 3 / \mathrm{C} 1)$.

\begin{tabular}{|c|c|c|c|c|c|c|c|c|c|c|}
\hline $\begin{array}{l}\text { Sample } \\
\text { size }\end{array}$ & Case & Model & $\mathrm{C} 1$ & $\mathrm{C} 2$ & $\mathrm{C} 3$ & $\mathrm{C} 4$ & $\mathrm{C} 3 / \mathrm{C} 2$ & $\mathrm{C} 4 / \mathrm{C} 2$ & $\mathrm{C} 4 / \mathrm{C} 3$ & $\mathrm{C} 3 / \mathrm{C} 1$ \\
\hline \multirow[t]{4}{*}{15} & \multirow[t]{2}{*}{10} & LAD & 0.36924 & 0.82319 & 0.17630 & 0.16583 & 0.214 & 0.201 & 0.941 & 0.477 \\
\hline & & LSD & 0.31192 & 0.75362 & 0.19886 & 0.17653 & 0.242 & 0.234 & 0.888 & 0.638 \\
\hline & \multirow[t]{2}{*}{6} & LAD & 0.36698 & 0.66307 & 0.24413 & 0.23173 & 0.368 & 0.349 & 0.949 & 0.665 \\
\hline & & LSD & 0.30599 & 0.59807 & 0.26934 & 0.24821 & 0.450 & 0.415 & 0.922 & 0.880 \\
\hline \multirow[t]{4}{*}{25} & \multirow[t]{2}{*}{10} & LAD & 0.36924 & 0.66658 & 0.26978 & 0.26159 & 0.405 & 0.392 & 0.970 & 0.731 \\
\hline & & LSD & 0.31192 & 0.60568 & 0.29496 & 0.28121 & 0.487 & 0.464 & 0.953 & 0.946 \\
\hline & \multirow[t]{2}{*}{6} & LAD & 0.36698 & 0.54840 & 0.28455 & 0.27086 & 0.519 & 0.494 & 0.952 & 0.775 \\
\hline & & LSD & 0.30599 & 0.50205 & 0.30704 & 0.29335 & 0.612 & 0.584 & 0.955 & 1.003 \\
\hline \multirow[t]{4}{*}{40} & \multirow[t]{2}{*}{10} & LAD & 0.36924 & 0.57417 & 0.30939 & 0.30583 & 0.539 & 0.533 & 0.988 & 0.838 \\
\hline & & LSD & 0.31192 & 0.52983 & 0.33079 & 0.32601 & 0.624 & 0.615 & 0.986 & 1.060 \\
\hline & \multirow[t]{2}{*}{6} & LAD & 0.36698 & 0.48241 & 0.30925 & 0.29728 & 0.641 & 0.616 & 0.961 & 0.843 \\
\hline & & LSD & 0.30599 & 0.44501 & 0.32037 & 0.31236 & 0.720 & 0.702 & 0.975 & 1.047 \\
\hline \multirow[t]{4}{*}{65} & \multirow[t]{2}{*}{10} & LAD & 0.36924 & 0.50310 & 0.33020 & 0.32513 & 0.656 & 0.646 & 0.985 & 0.894 \\
\hline & & LSD & 0.31192 & 0.46771 & 0.34046 & 0.33620 & 0.728 & 0.719 & 0.987 & 1.091 \\
\hline & \multirow[t]{2}{*}{6} & LAD & 0.36698 & 0.43752 & 0.32591 & 0.31565 & 0.745 & 0.721 & 0.967 & 0.888 \\
\hline & & LSD & 0.30599 & 0.39896 & 0.32084 & 0.31322 & 0.804 & 0.785 & 0.976 & 1.049 \\
\hline \multirow[t]{4}{*}{100} & \multirow[t]{2}{*}{10} & LAD & 0.36924 & 0.45960 & 0.34149 & 0.33438 & 0.743 & 0.728 & 0.979 & 0.925 \\
\hline & & LSD & 0.31192 & 0.42314 & 0.33801 & 0.33372 & 0.799 & 0.772 & 0.987 & 1.084 \\
\hline & \multirow[t]{2}{*}{6} & LAD & 0.36698 & 0.41285 & 0.33750 & 0.32911 & 0.817 & 0.797 & 0.975 & 0.920 \\
\hline & & LSD & 0.30599 & 0.36963 & 0.31813 & 0.31226 & 0.861 & 0.845 & 0.982 & 1.040 \\
\hline \multirow[t]{4}{*}{160} & \multirow[t]{2}{*}{10} & LAD & 0.36924 & 0.42656 & 0.34929 & 0.34577 & 0.819 & 0.811 & 0.990 & 0.946 \\
\hline & & LSD & 0.31192 & 0.38503 & 0.33172 & 0.32978 & 0.862 & 0.857 & 0.994 & 1.063 \\
\hline & \multirow[t]{2}{*}{6} & LAD & 0.36698 & 0.39421 & 0.34556 & 0.34131 & 0.877 & 0.866 & 0.988 & 0.942 \\
\hline & & LSD & 0.30599 & 0.34668 & 0.31471 & 0.31177 & 0.908 & 0.899 & 0.991 & 1.028 \\
\hline \multirow[t]{4}{*}{250} & \multirow[t]{2}{*}{10} & LAD & 0.36924 & 0.40505 & 0.35441 & 0.35257 & 0.875 & 0.870 & 0.995 & 0.960 \\
\hline & & LSD & 0.31192 & 0.35909 & 0.32608 & 0.32541 & 0.908 & 0.906 & 0.998 & 1.045 \\
\hline & \multirow[t]{2}{*}{6} & LAD & 0.36698 & 0.38328 & 0.35161 & 0.34934 & 0.917 & 0.911 & 0.994 & 0.958 \\
\hline & & LSD & 0.30599 & 0.33194 & 0.31188 & 0.31066 & 0.940 & 0.936 & 0.996 & 1.019 \\
\hline \multirow[t]{4}{*}{500} & \multirow[t]{2}{*}{10} & LAD & 0.36924 & 0.38708 & 0.36071 & 0.35695 & 0.932 & 0.922 & 0.990 & 0.977 \\
\hline & & LSD & 0.31192 & 0.33582 & 0.32013 & 0.31692 & 0.953 & 0.944 & 0.990 & 1.026 \\
\hline & \multirow[t]{2}{*}{6} & LAD & 0.36698 & 0.37622 & 0.36011 & 0.35656 & 0.957 & 0.948 & 0.990 & 0.981 \\
\hline & & LSD & 0.30599 & 0.31932 & 0.30961 & 0.30651 & 0.970 & 0.960 & 0.990 & 1.012 \\
\hline
\end{tabular}

provides a comprehensive comparison of various measures of agreement.

In this simulation study, the measure of agreement for both the LAD and LSD prediction equations is given by

$$
\rho=1-\frac{\delta}{\mu_{\delta}},
$$

where

$$
\delta=\frac{1}{n} \sum_{i=1}^{n}\left|y_{i}-\tilde{y}_{i}\right|
$$

and $\mu_{\delta}$ is the average value of $\delta$ over all $n$ ! equally likely permutations of $y_{1}, \ldots, y_{n}$ relative to $\tilde{y}_{1}, \ldots, \tilde{y}_{n}$ under the null hypothesis that the $n$ pairs $\left(y_{i}\right.$ and $\tilde{y}_{i}$ for $i=1, \ldots, n)$ are merely the result of random assignment. This reduces to the simple computational form given by

$$
\mu_{\delta}=\frac{1}{n^{2}} \sum_{i=1}^{n} \sum_{j=1}^{n}\left|y_{i}-\tilde{y}_{j}\right| .
$$

Since $\rho$ is a chance-corrected measure of agreement, $\rho$ $=1.0$ implies that all paired values of $y_{i}$ and $\tilde{y}_{i}$ for $i=$
$1, \ldots, n$ fall on a line with unit slope that passes through the origin (i.e., a perfect forecast). The choice of $\rho$ rather than the Pearson product-moment correlation coefficient ( $r)$ or $r^{2}$ (the coefficient of determination) is that the latter are measures of linearity and not measures of agreement. Also, the choice of the mean absolute error for $\delta$ rather than the mean squared error is that extreme values influence the squared Euclidean differences of the MSE far more than the Euclidean differences of the MAE. These choices are elaborated by Mielke et al. (1996).

\section{Data and simulation procedures}

The present study investigates the accuracy and utility of a single-sample estimator of shrinkage. Also considered are the effects of sample size, type of regression model (LAD and LSD), and noise-to-signal ratio in five populations that differ in amount and degree of contaminated data. Sample sizes $(n)$ of $15,25,40,65,100$, 160,250 , and 500 events are obtained from a fixed population of $N=3958$ events, which, for the purpose of this study, is not contaminated with extreme cases; 
TABle 5. Population 5: Contaminated population of 4158 events of the initial population of 3958 events and 200 very extreme events. Columns are (C1) true population $\rho$ values, (C2) average of 10000 sample $\hat{\rho}$ values based on regression coefficients for each sample, (C3) average of five sample $\hat{\rho}$ values for each of 10000 random sets of regression coefficients associated with the 10000 samples of C2, (C4) average of 10000 drop-one $\hat{\rho}$ values estimated for each of the 10000 samples of $\mathrm{C} 2$, and corresponding ratios (C3/C2), (C4/C2), (C4/C3), and $(\mathrm{C} 3 / \mathrm{C} 1)$.

\begin{tabular}{|c|c|c|c|c|c|c|c|c|c|c|}
\hline $\begin{array}{l}\text { Sample } \\
\text { size }\end{array}$ & Case & Model & $\mathrm{C} 1$ & $\mathrm{C} 2$ & $\mathrm{C} 3$ & $\mathrm{C} 4$ & $\mathrm{C} 3 / \mathrm{C} 2$ & $\mathrm{C} 4 / \mathrm{C} 2$ & $\mathrm{C} 4 / \mathrm{C} 3$ & $\mathrm{C} 3 / \mathrm{C} 1$ \\
\hline \multirow[t]{4}{*}{15} & \multirow[t]{2}{*}{10} & LAD & 0.16541 & 0.82410 & 0.15671 & 0.14784 & 0.190 & 0.179 & 0.943 & 0.947 \\
\hline & & LSD & 0.13645 & 0.75637 & 0.17684 & 0.15684 & 0.234 & 0.207 & 0.887 & 1.296 \\
\hline & \multirow[t]{2}{*}{6} & LAD & 0.10284 & 0.65648 & 0.21212 & 0.21141 & 0.323 & 0.322 & 0.997 & 2.063 \\
\hline & & LSD & 0.08999 & 0.59195 & 0.23220 & 0.22483 & 0.392 & 0.380 & 0.968 & 2.580 \\
\hline \multirow[t]{4}{*}{25} & \multirow[t]{2}{*}{10} & LAD & 0.16541 & 0.67046 & 0.23397 & 0.22978 & 0.349 & 0.343 & 0.982 & 1.414 \\
\hline & & LSD & 0.13645 & 0.61289 & 0.25467 & 0.24579 & 0.416 & 0.401 & 0.965 & 1.866 \\
\hline & \multirow[t]{2}{*}{6} & LAD & 0.10284 & 0.52745 & 0.22739 & 0.22995 & 0.431 & 0.436 & 1.011 & 2.211 \\
\hline & & LSD & 0.08999 & 0.48267 & 0.24628 & 0.24774 & 0.467 & 0.513 & 1.006 & 2.737 \\
\hline \multirow[t]{4}{*}{40} & \multirow[t]{2}{*}{10} & LAD & 0.16541 & 0.57754 & 0.26244 & 0.26566 & 0.454 & 0.460 & 1.012 & 1.587 \\
\hline & & LSD & 0.13645 & 0.53669 & 0.27945 & 0.28149 & 0.521 & 0.524 & 1.007 & 2.048 \\
\hline & \multirow[t]{2}{*}{6} & LAD & 0.10284 & 0.42604 & 0.21735 & 0.22235 & 0.510 & 0.522 & 1.023 & 2.113 \\
\hline & & LSD & 0.08999 & 0.39821 & 0.23444 & 0.24104 & 0.589 & 0.605 & 1.028 & 2.605 \\
\hline \multirow[t]{4}{*}{65} & \multirow[t]{2}{*}{10} & LAD & 0.16541 & 0.48744 & 0.26077 & 0.26526 & 0.535 & 0.544 & 1.017 & 1.577 \\
\hline & & LSD & 0.13645 & 0.46297 & 0.27581 & 0.27978 & 0.596 & 0.604 & 1.014 & 2.021 \\
\hline & \multirow[t]{2}{*}{6} & LAD & 0.10284 & 0.33718 & 0.19921 & 0.19730 & 0.591 & 0.585 & 0.990 & 1.937 \\
\hline & & LSD & 0.08999 & 0.30874 & 0.20295 & 0.20390 & 0.657 & 0.660 & 1.005 & 2.255 \\
\hline \multirow[t]{4}{*}{100} & \multirow[t]{2}{*}{10} & LAD & 0.16541 & 0.40913 & 0.24710 & 0.24839 & 0.604 & 0.607 & 1.005 & 1.494 \\
\hline & & LSD & 0.13645 & 0.38873 & 0.25578 & 0.25838 & 0.658 & 0.665 & 1.010 & 1.875 \\
\hline & \multirow[t]{2}{*}{6} & LAD & 0.10284 & 0.27822 & 0.18593 & 0.18110 & 0.668 & 0.651 & 0.974 & 1.808 \\
\hline & & LSD & 0.08999 & 0.23511 & 0.17010 & 0.16837 & 0.723 & 0.716 & 0.990 & 1.890 \\
\hline \multirow{4}{*}{160} & \multirow[t]{2}{*}{10} & LAD & 0.16541 & 0.33696 & 0.23219 & 0.23301 & 0.689 & 0.692 & 1.004 & 1.404 \\
\hline & & LSD & 0.13645 & 0.30317 & 0.22288 & 0.22643 & 0.735 & 0.747 & 1.016 & 1.633 \\
\hline & \multirow[t]{2}{*}{6} & LAD & 0.10284 & 0.23075 & 0.17241 & 0.16991 & 0.747 & 0.736 & 0.985 & 1.676 \\
\hline & & LSD & 0.08999 & 0.17580 & 0.14063 & 0.13848 & 0.800 & 0.788 & 0.985 & 1.563 \\
\hline \multirow[t]{4}{*}{250} & \multirow[t]{2}{*}{10} & LAD & 0.16541 & 0.28582 & 0.21974 & 0.22088 & 0.769 & 0.773 & 1.005 & 1.328 \\
\hline & & LSD & 0.13645 & 0.23539 & 0.19305 & 0.19305 & 0.820 & 0.820 & 1.000 & 1.415 \\
\hline & \multirow[t]{2}{*}{6} & LAD & 0.10284 & 0.19584 & 0.15837 & 0.15498 & 0.809 & 0.791 & 0.979 & 1.540 \\
\hline & & LSD & 0.08999 & 0.13849 & 0.11975 & 0.11718 & 0.865 & 0.846 & 0.979 & 1.331 \\
\hline \multirow[t]{4}{*}{500} & \multirow[t]{2}{*}{10} & LAD & 0.16541 & 0.23315 & 0.20148 & 0.19745 & 0.864 & 0.847 & 0.980 & 1.218 \\
\hline & & LSD & 0.13645 & 0.17699 & 0.16198 & 0.15951 & 0.915 & 0.901 & 0.985 & 1.187 \\
\hline & \multirow[t]{2}{*}{6} & LAD & 0.10284 & 0.15889 & 0.14052 & 0.13570 & 0.884 & 0.854 & 0.966 & 1.366 \\
\hline & & LSD & 0.08999 & 0.11112 & 0.10326 & 0.09952 & 0.929 & 0.896 & 0.964 & 1.147 \\
\hline
\end{tabular}

a fixed population of $N=3998$ events consisting of the initial population and 40 moderately extreme events $(1 \%$ moderate contamination); a fixed population of $N=$ 3998 events consisting of the initial population and 40 very extreme events (1\% severe contamination); a fixed population of $N=4158$ events consisting of the initial population and 200 moderately extreme events (5\% moderate contamination); and a fixed population of $N$

TABLE 6. Probability of no contaminated values in each sample of size $n$.

\begin{tabular}{ccc}
\hline \hline & \multicolumn{2}{c}{ Contamination } \\
\cline { 2 - 3 } Sample size $(n)$ & $1 \%$ & $5 \%$ \\
\hline 15 & 0.8600 & 0.4774 \\
25 & 0.7777 & 0.2916 \\
40 & 0.6688 & 0.1392 \\
65 & 0.5202 & 0.0406 \\
100 & 0.3658 & 0.0072 \\
160 & 0.2001 & 0.0004 \\
250 & 0.0810 & $4.4 \times 10^{-6}$ \\
500 & 0.0066 & $2.0 \times 10^{-11}$ \\
\hline
\end{tabular}

$=4158$ events consisting of the initial population and 200 very extreme events ( $5 \%$ severe contamination). The 3958 available primary events used to construct each of the five populations used in this study consist of a response variable and $p=10$ predictor variables. Specifics of the meteorological data used to construct these five populations are given in Mielke et al. (1996).

Two prediction models are considered for each of the five populations. The first prediction model (case 10) consists of $p=10$ independent variables, and the second prediction model (case 6) consists of $p=6$ independent variables. In case 10, 4 of the 10 independent variables in the initial population of $N=3958$ events were found to contribute no information to the predictions. Case 6 is merely the prediction model with the four noninformative independent variables of case 10 deleted. Both the case 10 and case 6 prediction models were constructed from the initial fixed population of $N=3958$ events. The reason for the two prediction models is to examine the effect of including noninformative independent variables (i.e., noise) in a prediction model. 
TABLE 7. Population 1: Initial population consisting of 3958 noncontaminated events. The $\operatorname{SD}(\hat{\rho} \mid \mathrm{C} 2)$ column contains the standard deviations of the $10000 \hat{\rho}$ values composing each $\mathrm{C} 2$ value in Table 1. The $\mathrm{SD}(\hat{\rho} \mid \mathrm{C} 4)$ column contains the standard deviations of the 10 000 drop-one $\hat{\rho}$ values composing each $\mathrm{C} 4$ value in Table 1 .

\begin{tabular}{|c|c|c|c|c|}
\hline $\begin{array}{c}\text { Sample } \\
\text { size }\end{array}$ & Case & Model & $\mathrm{SD}(\hat{\rho} \mid \mathrm{C} 2)$ & $\mathrm{SD}(\hat{\rho} \mid \mathrm{C} 4)$ \\
\hline \multirow[t]{4}{*}{15} & \multirow[t]{2}{*}{10} & LAD & 0.07205 & 0.21811 \\
\hline & & LSD & 0.10145 & 0.20870 \\
\hline & \multirow[t]{2}{*}{6} & LAD & 0.10536 & 0.23722 \\
\hline & & LSD & 0.12495 & 0.21354 \\
\hline \multirow[t]{4}{*}{25} & \multirow[t]{2}{*}{10} & LAD & 0.07976 & 0.19051 \\
\hline & & LSD & 0.09381 & 0.15925 \\
\hline & \multirow[t]{2}{*}{6} & LAD & 0.09650 & 0.18076 \\
\hline & & LSD & 0.10405 & 0.15057 \\
\hline \multirow[t]{4}{*}{40} & \multirow[t]{2}{*}{10} & LAD & 0.07542 & 0.14298 \\
\hline & & LSD & 0.08140 & 0.11277 \\
\hline & \multirow[t]{2}{*}{6} & LAD & 0.08507 & 0.13386 \\
\hline & & LSD & 0.08608 & 0.10771 \\
\hline \multirow[t]{4}{*}{65} & \multirow[t]{2}{*}{10} & LAD & 0.06600 & 0.10259 \\
\hline & & LSD & 0.06736 & 0.08098 \\
\hline & \multirow[t]{2}{*}{6} & LAD & 0.07015 & 0.09610 \\
\hline & & LSD & 0.06946 & 0.07882 \\
\hline \multirow[t]{4}{*}{100} & \multirow[t]{2}{*}{10} & LAD & 0.05482 & 0.07727 \\
\hline & & LSD & 0.05479 & 0.06276 \\
\hline & \multirow[t]{2}{*}{6} & LAD & 0.05717 & 0.07272 \\
\hline & & LSD & 0.05582 & 0.06118 \\
\hline \multirow[t]{4}{*}{160} & \multirow[t]{2}{*}{10} & LAD & 0.04579 & 0.05734 \\
\hline & & LSD & 0.04508 & 0.04804 \\
\hline & \multirow[t]{2}{*}{6} & LAD & 0.04702 & 0.05450 \\
\hline & & LSD & 0.04545 & 0.04737 \\
\hline \multirow[t]{4}{*}{250} & \multirow[t]{2}{*}{10} & LAD & 0.03696 & 0.04148 \\
\hline & & LSD & 0.03620 & 0.03692 \\
\hline & \multirow[t]{2}{*}{6} & LAD & 0.03762 & 0.04071 \\
\hline & & LSD & 0.03636 & 0.03651 \\
\hline \multirow[t]{4}{*}{500} & \multirow[t]{2}{*}{10} & LAD & 0.02695 & 0.02921 \\
\hline & & LSD & 0.02622 & 0.02684 \\
\hline & \multirow[t]{2}{*}{6} & LAD & 0.02717 & 0.02884 \\
\hline & & LSD & 0.02615 & 0.02679 \\
\hline
\end{tabular}

\section{Findings and discussion}

The results of the study are summarized in Tables 15. In Tables $1-5$, each row is specified by 1 ) a sample size $(n), 2) p=10$ (case 10) and $p=6$ (case 6) independent samples, and 3) LAD and LSD regression analyses. In each of the five tables the first column $(\mathrm{C} 1)$ contains the true $\rho$ values for the designated population and the second column $(\mathrm{C} 2)$ contains the average of 10000 randomly obtained sample estimates of $\rho, \hat{\rho}$, where the $\tilde{y}$ values are based on the sample regression coefficients for each of the 10000 independent samples, that is, a measure of retrospective fit. The third column (C3) measures the effectiveness of validating sample regression coefficients. In this column the sample regression coefficients from 10000 random samples were first obtained from column $\mathrm{C} 2$, then for each of these 10000 sets of sample regression coefficients an additional five independent random samples of the same size $(n=15, \ldots, 500)$ were drawn from the population. The sample regression coefficients from $\mathrm{C} 2$ were then applied to each of the five new samples, and $\hat{\rho}$ values were computed for each of these five samples for a total
TABLE 8. Population 2: Contaminated population of 3998 events consisting of the initial population of 3958 events and 40 moderately extreme events. The $\operatorname{SD}(\hat{\rho} \mid \mathrm{C} 2)$ column contains the standard deviations of the $10000 \hat{\rho}$ values composing each $\mathrm{C} 2$ value in Table 2 . The $\operatorname{SD}(\hat{\rho} \mid \mathrm{C} 4)$ column contains the standard deviations of the 10000 drop-one $\hat{\rho}$ values composing each $\mathrm{C} 4$ value in Table 2.

\begin{tabular}{|c|c|c|c|c|}
\hline $\begin{array}{l}\text { Sample } \\
\text { size }\end{array}$ & Case & Model & $\mathrm{SD}(\hat{\rho} \mid \mathrm{C} 2)$ & $\mathrm{SD}(\hat{\rho} \mid \mathrm{C} 4)$ \\
\hline \multirow[t]{4}{*}{15} & \multirow[t]{2}{*}{10} & LAD & 0.07354 & 0.21597 \\
\hline & & LSD & 0.10359 & 0.20627 \\
\hline & \multirow[t]{2}{*}{6} & LAD & 0.10890 & 0.23385 \\
\hline & & LSD & 0.12936 & 0.21345 \\
\hline \multirow[t]{4}{*}{25} & \multirow[t]{2}{*}{10} & LAD & 0.08266 & 0.18894 \\
\hline & & LSD & 0.09707 & 0.15777 \\
\hline & \multirow[t]{2}{*}{6} & LAD & 0.10427 & 0.18602 \\
\hline & & LSD & 0.11167 & 0.15612 \\
\hline \multirow[t]{4}{*}{40} & \multirow[t]{2}{*}{10} & LAD & 0.07913 & 0.14657 \\
\hline & & LSD & 0.08435 & 0.11843 \\
\hline & \multirow[t]{2}{*}{6} & LAD & 0.09503 & 0.14472 \\
\hline & & LSD & 0.09713 & 0.12155 \\
\hline \multirow[t]{4}{*}{65} & \multirow[t]{2}{*}{10} & LAD & 0.07164 & 0.11311 \\
\hline & & LSD & 0.07299 & 0.09119 \\
\hline & \multirow[t]{2}{*}{6} & LAD & 0.08132 & 0.11164 \\
\hline & & LSD & 0.08418 & 0.09778 \\
\hline \multirow[t]{4}{*}{100} & \multirow[t]{2}{*}{10} & LAD & 0.06286 & 0.08795 \\
\hline & & LSD & 0.06408 & 0.07473 \\
\hline & \multirow[t]{2}{*}{6} & LAD & 0.06886 & 0.08581 \\
\hline & & LSD & 0.07336 & 0.08112 \\
\hline \multirow[t]{4}{*}{160} & \multirow[t]{2}{*}{10} & LAD & 0.05246 & 0.06648 \\
\hline & & LSD & 0.05481 & 0.06168 \\
\hline & \multirow[t]{2}{*}{6} & LAD & 0.05509 & 0.06478 \\
\hline & & LSD & 0.06151 & 0.06593 \\
\hline \multirow[t]{4}{*}{250} & \multirow[t]{2}{*}{10} & LAD & 0.04379 & 0.05167 \\
\hline & & LSD & 0.04796 & 0.05224 \\
\hline & \multirow[t]{2}{*}{6} & LAD & 0.04497 & 0.04962 \\
\hline & & LSD & 0.05194 & 0.05471 \\
\hline \multirow[t]{4}{*}{500} & \multirow[t]{2}{*}{10} & LAD & 0.03150 & 0.03451 \\
\hline & & LSD & 0.03697 & 0.03729 \\
\hline & \multirow[t]{2}{*}{6} & LAD & 0.03189 & 0.03289 \\
\hline & & LSD & 0.03864 & 0.03872 \\
\hline
\end{tabular}

of $50000 \hat{\rho}$ values. The average of the $50000 \hat{\rho}$ values is reported in column $\mathrm{C} 3$, yielding a measure of validation fit. The fourth column (C4) contains the average of 10000 randomly obtained drop-one sample $\hat{\rho}$ values where each of the $\hat{\rho}$ values is based on the same sample data that yields one of the 10000 sample $\hat{\rho}$ values composing the averages in column $\mathrm{C} 2$. Thus, each value in column C4 represents the average of $n$ times $10000 \hat{\rho}$ values. The fifth column $(\mathrm{C} 3 / \mathrm{C} 2)$ contains the ratio of the average $\hat{\rho}$ value of $\mathrm{C} 3$ to the corresponding $\hat{\rho}$ value of $\mathrm{C} 2$, that is, the index of shrinkage. The sixth column $(\mathrm{C} 4 / \mathrm{C} 2)$ contains the ratio of the average $\hat{\rho}$ value of $\mathrm{C} 4$ to the average $\hat{\rho}$ value of $\mathrm{C} 2$, that is, the drop-one singlesample estimator of shrinkage, as measured by $\mathrm{C} 3 / \mathrm{C} 2$. The seventh column $(\mathrm{C} 4 / \mathrm{C} 3)$ contains the ratio of the average $\hat{\rho}$ value of $\mathrm{C} 4 / \mathrm{C} 2$ to the average $\hat{\rho}$ value of $\mathrm{C} 3 / \mathrm{C} 2$, that is, the ratio of the drop-one single-sample estimator of shrinkage to the index of shrinkage. The eighth column $(\mathrm{C} 3 / \mathrm{C} 1)$ contains the ratio of the validation fit of $\mathrm{C} 3$ to the corresponding true fit, measured by the population $\rho$ value given in $\mathrm{C} 1$. The values of 
TABLE 9. Population 3: Contaminated population consisting of 3998 events consisting of the initial population of 3958 events and 40 very extreme events. The $\operatorname{SD}(\hat{\rho} \mid \mathrm{C} 2)$ column contains the standard deviations of the $10000 \hat{\rho}$ values composing each $\mathrm{C} 2$ value in Table 3 . The $\mathrm{SD}(\hat{\rho} \mid \mathrm{C} 4)$ column contains the standard deviations of the 10000 drop-one $\hat{\rho}$ values composing each $\mathrm{C} 4$ value in Table 3.

\begin{tabular}{|c|c|c|c|c|}
\hline $\begin{array}{l}\text { Sample } \\
\text { size }\end{array}$ & Case & Model & $\mathrm{SD}(\hat{\rho} \mid \mathrm{C} 2)$ & $\mathrm{SD}(\hat{\rho} \mid \mathrm{C} 4)$ \\
\hline \multirow[t]{4}{*}{15} & \multirow[t]{2}{*}{10} & LAD & 0.07312 & 0.21340 \\
\hline & & LSD & 0.10296 & 0.20394 \\
\hline & \multirow[t]{2}{*}{6} & LAD & 0.10986 & 0.23235 \\
\hline & & LSD & 0.13057 & 0.21374 \\
\hline \multirow[t]{4}{*}{25} & \multirow[t]{2}{*}{10} & LAD & 0.08271 & 0.18859 \\
\hline & & LSD & 0.09680 & 0.16023 \\
\hline & \multirow[t]{2}{*}{6} & LAD & 0.10943 & 0.19101 \\
\hline & & LSD & 0.11702 & 0.16443 \\
\hline \multirow[t]{4}{*}{40} & \multirow[t]{2}{*}{10} & LAD & 0.07881 & 0.15062 \\
\hline & & LSD & 0.08353 & 0.12591 \\
\hline & \multirow[t]{2}{*}{6} & LAD & 0.10850 & 0.16098 \\
\hline & & LSD & 0.10854 & 0.14063 \\
\hline \multirow[t]{4}{*}{65} & \multirow[t]{2}{*}{10} & LAD & 0.07311 & 0.12111 \\
\hline & & LSD & 0.07326 & 0.10234 \\
\hline & \multirow[t]{2}{*}{6} & LAD & 0.10760 & 0.14048 \\
\hline & & LSD & 0.10912 & 0.13000 \\
\hline \multirow[t]{4}{*}{100} & \multirow[t]{2}{*}{10} & LAD & 0.07011 & 0.10276 \\
\hline & & LSD & 0.06856 & 0.09096 \\
\hline & \multirow[t]{2}{*}{6} & LAD & 0.09916 & 0.12123 \\
\hline & & LSD & 0.10987 & 0.12467 \\
\hline \multirow[t]{4}{*}{160} & \multirow[t]{2}{*}{10} & LAD & 0.06532 & 0.09020 \\
\hline & & LSD & 0.06718 & 0.08629 \\
\hline & \multirow[t]{2}{*}{6} & LAD & 0.08366 & 0.09932 \\
\hline & & LSD & 0.10760 & 0.11722 \\
\hline \multirow[t]{4}{*}{250} & \multirow[t]{2}{*}{10} & LAD & 0.06024 & 0.07645 \\
\hline & & LSD & 0.07112 & 0.08589 \\
\hline & \multirow[t]{2}{*}{6} & LAD & 0.07153 & 0.08012 \\
\hline & & LSD & 0.10170 & 0.10799 \\
\hline \multirow[t]{4}{*}{500} & \multirow[t]{2}{*}{10} & LAD & 0.04760 & 0.05133 \\
\hline & & LSD & 0.07220 & 0.07339 \\
\hline & \multirow[t]{2}{*}{6} & LAD & 0.05308 & 0.05542 \\
\hline & & LSD & 0.08288 & 0.08283 \\
\hline
\end{tabular}

columns $\mathrm{C} 1, \mathrm{C} 2, \mathrm{C} 3, \mathrm{C} 3 / \mathrm{C} 2$, and $\mathrm{C} 3 / \mathrm{C} 1$ are contained in Mielke et al. (1996).

It should be noted in this context that both $\mathrm{C} 3$ and $\mathrm{C} 4$ are free from any selection bias. Selection bias occurs when a subset of predictor variables is selected from the full set of predictor variables in the population based on information contained in the sample. In this study, selection bias has been controlled by selecting the two sets of predictor variables (i.e., cases 10 and 6) from information contained in the population and not from information contained in any sample. Specifically, in the case of $\mathrm{C} 3$, the predictor variables were selected from information in the population, the regression coefficients were based on information contained in the sample for these (10 or 6) predetermined predictor variables, then the regression coefficients were applied to five new independent samples of the same size and drawn from the same population. This process was repeated for 10000 samples, producing $50000 \hat{\rho}$ values. Each C3 value is an average of these $50000 \hat{\rho}$ values. Thus, while there is an optimizing bias due to retrospective fit, there is no selection bias. In the case of $\mathrm{C} 4$,
TABLE 10. Population 4: Contaminated population consisting of 4158 events consisting of the initial population of 3958 events and 200 moderately extreme events. The $\mathrm{SD}(\hat{\rho} \mid \mathrm{C} 2)$ column contains the standard deviations of the $10000 \hat{\rho}$ values composing each $\mathrm{C} 2$ value in Table 4. The $\operatorname{SD}(\hat{\rho} \mid \mathrm{C} 4)$ column contains the standard deviations of the 10000 drop-one $\hat{\rho}$ values composing each $\mathrm{C} 4$ value in Table 4 .

\begin{tabular}{|c|c|c|c|c|}
\hline $\begin{array}{c}\text { Sample } \\
\text { size }\end{array}$ & Case & Model & $\mathrm{SD}(\hat{\rho} \mid \mathrm{C} 2)$ & $\mathrm{SD}(\hat{\rho} \mid \mathrm{C} 4)$ \\
\hline \multirow[t]{4}{*}{15} & \multirow[t]{2}{*}{10} & LAD & 0.07562 & 0.20328 \\
\hline & & LSD & 0.10652 & 0.19460 \\
\hline & \multirow[t]{2}{*}{6} & LAD & 0.12349 & 0.23447 \\
\hline & & LSD & 0.14319 & 0.21392 \\
\hline \multirow[t]{4}{*}{25} & \multirow[t]{2}{*}{10} & LAD & 0.09434 & 0.18918 \\
\hline & & LSD & 0.10862 & 0.16428 \\
\hline & \multirow[t]{2}{*}{6} & LAD & 0.13018 & 0.19988 \\
\hline & & LSD & 0.13574 & 0.17395 \\
\hline \multirow[t]{4}{*}{40} & \multirow[t]{2}{*}{10} & LAD & 0.09796 & 0.16053 \\
\hline & & LSD & 0.10279 & 0.13597 \\
\hline & \multirow[t]{2}{*}{6} & LAD & 0.12286 & 0.16902 \\
\hline & & LSD & 0.12368 & 0.14667 \\
\hline \multirow[t]{4}{*}{65} & \multirow[t]{2}{*}{10} & LAD & 0.09569 & 0.13179 \\
\hline & & LSD & 0.09648 & 0.11449 \\
\hline & \multirow[t]{2}{*}{6} & LAD & 0.11052 & 0.13891 \\
\hline & & LSD & 0.10641 & 0.11780 \\
\hline \multirow[t]{4}{*}{100} & \multirow[t]{2}{*}{10} & LAD & 0.08759 & 0.10968 \\
\hline & & LSD & 0.08668 & 0.09591 \\
\hline & \multirow[t]{2}{*}{6} & LAD & 0.09751 & 0.11473 \\
\hline & & LSD & 0.09047 & 0.09552 \\
\hline \multirow[t]{4}{*}{160} & \multirow[t]{2}{*}{10} & LAD & 0.07687 & 0.08986 \\
\hline & & LSD & 0.07262 & 0.07640 \\
\hline & \multirow[t]{2}{*}{6} & LAD & 0.08342 & 0.09390 \\
\hline & & LSD & 0.07305 & 0.07508 \\
\hline \multirow[t]{4}{*}{250} & \multirow[t]{2}{*}{10} & LAD & 0.06777 & 0.07482 \\
\hline & & LSD & 0.05996 & 0.06017 \\
\hline & \multirow[t]{2}{*}{6} & LAD & 0.07159 & 0.07611 \\
\hline & & LSD & 0.05947 & 0.05962 \\
\hline \multirow[t]{4}{*}{500} & \multirow[t]{2}{*}{10} & LAD & 0.05184 & 0.05465 \\
\hline & & LSD & 0.04164 & 0.04147 \\
\hline & \multirow[t]{2}{*}{6} & LAD & 0.05314 & 0.05635 \\
\hline & & LSD & 0.04148 & 0.04148 \\
\hline
\end{tabular}

the predictor variables were again selected from information contained in the population and the regression coefficients were based on information contained in the sample, after dropping one observation. A $\hat{\rho}$ value was calculated on the set of $n-1 y$ and $\tilde{y}$ values, and the procedure was repeated $n$ times, dropping a different observation each time. The entire process was repeated for 10000 samples, producing $n$ times $10000 \hat{\rho}$ values. Each C4 value is an average of these $n$ times 10000 $\hat{\rho}$ values. Thus, there is no selection bias. The advantage to this approach is that the optimizing bias can be isolated and examined while the selection bias is controlled. In addition, this approach is more conservative as validation fit is almost always better when subset selection is included (MacCallum et al. 1994). The drawback to this approach is that the results cannot be generalized to studies that selected both prediction variables and regression coefficients based on sample information and, in addition, shrinkage may be increased.

The ratio values in column $\mathrm{C} 3 / \mathrm{C} 2$ in Tables $1-5$ provide a comprehensive index of shrinkage that serves as a benchmark against which the accuracy of the drop- 
TABLE 11. Population 5: Contaminated population consisting of 4158 events consisting of the initial population of 3958 events and 200 very extreme events. The $\mathrm{SD}(\hat{\rho} \mid \mathrm{C} 2)$ column contains the standard deviations of the $10000 \hat{\rho}$ values composing each $\mathrm{C} 2$ value in Table 5. The $\mathrm{SD}(\hat{\rho} \mid \mathrm{C} 4)$ column contains the standard deviations of the 10 000 drop-one $\hat{\rho}$ values composing each $\mathrm{C} 4$ value in Table 5.

\begin{tabular}{|c|c|c|c|c|}
\hline $\begin{array}{l}\text { Sample } \\
\text { size }\end{array}$ & Case & Model & $\mathrm{SD}(\hat{\rho} \mid \mathrm{C} 2)$ & $\mathrm{SD}(\hat{\rho} \mid \mathrm{C} 4)$ \\
\hline \multirow[t]{4}{*}{15} & \multirow[t]{2}{*}{10} & LAD & 0.07494 & 0.19074 \\
\hline & & LSD & 0.10476 & 0.18378 \\
\hline & \multirow[t]{2}{*}{6} & LAD & 0.12873 & 0.22530 \\
\hline & & LSD & 0.14899 & 0.20967 \\
\hline \multirow[t]{4}{*}{25} & \multirow[t]{2}{*}{10} & LAD & 0.09339 & 0.17836 \\
\hline & & LSD & 0.10667 & 0.16084 \\
\hline & \multirow[t]{2}{*}{6} & LAD & 0.14751 & 0.20186 \\
\hline & & LSD & 0.15292 & 0.15169 \\
\hline \multirow[t]{4}{*}{40} & \multirow[t]{2}{*}{10} & LAD & 0.10061 & 0.15998 \\
\hline & & LSD & 0.10400 & 0.14360 \\
\hline & \multirow[t]{2}{*}{6} & LAD & 0.15666 & 0.18604 \\
\hline & & LSD & 0.15555 & 0.17129 \\
\hline \multirow[t]{4}{*}{65} & \multirow[t]{2}{*}{10} & LAD & 0.11479 & 0.14447 \\
\hline & & LSD & 0.11073 & 0.13048 \\
\hline & \multirow[t]{2}{*}{6} & LAD & 0.15084 & 0.15964 \\
\hline & & LSD & 0.14880 & 0.14895 \\
\hline \multirow[t]{4}{*}{100} & \multirow[t]{2}{*}{10} & LAD & 0.11799 & 0.12954 \\
\hline & & LSD & 0.11559 & 0.12049 \\
\hline & \multirow[t]{2}{*}{6} & LAD & 0.13551 & 0.13828 \\
\hline & & LSD & 0.12614 & 0.12206 \\
\hline \multirow[t]{4}{*}{160} & \multirow[t]{2}{*}{10} & LAD & 0.10895 & 0.11034 \\
\hline & & LSD & 0.10701 & 0.10334 \\
\hline & \multirow[t]{2}{*}{6} & LAD & 0.11705 & 0.11682 \\
\hline & & LSD & 0.09116 & 0.08748 \\
\hline \multirow[t]{4}{*}{250} & \multirow[t]{2}{*}{10} & LAD & 0.09543 & 0.09467 \\
\hline & & LSD & 0.08361 & 0.07840 \\
\hline & \multirow[t]{2}{*}{6} & LAD & 0.10046 & 0.09831 \\
\hline & & LSD & 0.06166 & 0.05949 \\
\hline \multirow[t]{4}{*}{500} & \multirow[t]{2}{*}{10} & LAD & 0.07177 & 0.06644 \\
\hline & & LSD & 0.04617 & 0.04218 \\
\hline & \multirow[t]{2}{*}{6} & LAD & 0.07518 & 0.07223 \\
\hline & & LSD & 0.03362 & 0.03134 \\
\hline
\end{tabular}

one single-sample estimator of shrinkage given in column $\mathrm{C} 4 / \mathrm{C} 2$ can be measured. The ratio values in column $\mathrm{C} 4 / \mathrm{C} 3$ were obtained by dividing the ratio values in column $\mathrm{C} 4 / \mathrm{C} 2$ by the corresponding ratio values in column $\mathrm{C} 3 / \mathrm{C} 2$. They provide the comparison ratio values by which the drop-one single-sample estimator of shrinkage is evaluated.

For each of the five populations summarized in Tables $1-5$, the ratio values in column $\mathrm{C} 4 / \mathrm{C} 3$ are close to unity for samples with $n>25$. The few C4/C3 values that exceed 1.0 are probably due to sampling error. It should be noted that the $\mathrm{C} 4 / \mathrm{C} 3$ ratios tend to be less than unity for the smaller sample sizes. When $n \leq 25$, reductions from unity of the $\mathrm{C} 4 / \mathrm{C} 3$ values are $4.5 \%-11 \%$ for the LAD regression model and $4.5 \%-15 \%$ for the LSD regression model in population 1. For populations 2-5, the corresponding reductions are 4\%-10\% (LAD) and $4.5 \%-14 \%$ (LSD), 3.5\%-9.5\% (LAD) and 3.5\%-14\% (LSD), 3\%-6\% (LAD) and 4.5\%-11\% (LSD), and 0\%$5.5 \%$ (LAD) and $0 \%-11 \%$ (LSD), respectively. Thus, the drop-one single-sample estimator (i.e., C4/C2) is an excellent estimator of shrinkage (i.e., C3/C2), although it is conservative for very small samples. This conclusion holds for all sample sizes greater than $n=25$, both cases (6 and 10), both regression models (LAD and LSD), and all five populations with differing degrees and amounts of data contamination.

Column $\mathrm{C} 3 / \mathrm{C} 1$ summarizes, in ratio format, the validation fit (C3) to the true population $\rho$ value $(\mathrm{C} 1)$. This is sometimes referred to as "expected skill" (Mielke et al. 1996). In general, the $\mathrm{C} 3 / \mathrm{C} 1$ values indicate the amount of skill that is expected relative to the true skill possible when an entire population is available. More specifically, the $\mathrm{C} 3 / \mathrm{C} 1$ values indicate the expected reduction in fit of the $y$ and $\tilde{y}$ values for future events (Mielke et al. 1996). A C3/C1 value that is greater than 1.0 is cause for concern since this indicates that the sample regression coefficients provide a better validation fit, on the average, than would have been possible had the actual population been available.

Inspection of column $\mathrm{C} 3 / \mathrm{C} 1$ in Table 1 reveals that the LSD regression model consistently performs better than the LAD regression model, case 10 has lower values than case 6 , and the $\mathrm{C} 3 / \mathrm{C} 1$ values increase with increasing sample size. Table 2 , with $1 \%$ moderate contamination, yields a few $\mathrm{C} 3 / \mathrm{C} 1$ values greater than 1.0 and they all appear with the LSD regression model. Table 3, with $1 \%$ severe contamination, shows the same pattern, but the $\mathrm{C} 3 / \mathrm{C} 1$ ratio values are somewhat higher. Table 4, with 5\% moderate contamination, continues the same motif and Table 5, with 5\% severe contamination, contains $\mathrm{C} 3 / \mathrm{C} 1$ values considerably greater than 1.0 for nearly every case. It is abundantly clear that with only a small amount of moderate or severe contamination, the LSD regression model produces inflated estimates of expected skill. The LAD regression model, based on absolute deviations about the median, is relatively unaffected by even $1 \%$ severe contamination, but the LSD regression model, based on squared deviations about the mean, systematically overestimates the validation fit and yields inflated values of expected skill (i.e., C3/C1).

Since C3 (validation fit $\hat{\rho}$ ) values and C4 (drop-one single-sample validation fit $\hat{\rho}$ ) values are essentially the same for all five populations, both cases, both regression models, and all sample sizes, it is readily apparent that $\mathrm{C} 4 / \mathrm{C} 1$ ratios would be nearly identical to the $\mathrm{C} 3 / \mathrm{C} 1$ ratios in Tables 1-5. Consequently, caution should be exercised in using drop-one estimators with the LSD regression model as they will likely provide inflated estimates of validation fit when contaminated data are present. Because the drop-one estimate of shrinkage is equivalent to dropone cross-validation, the same caution applies to drop-one cross-validation with an LSD regression model.

While it is abundantly evident that LSD regression systematically overestimates validation fit, the reason for the optimistic $\mathrm{C} 3 / \mathrm{C} 1$ values is not as manifest. It is obvious that the inflated estimates of expected skill for LSD regression in Tables 1-5 are systematically related to sample size with larger sample sizes associated with $\mathrm{C} 3 / \mathrm{C} 1$ values in excess of 1.0. This is probably due to a moderately or 
severely contaminated population event occurring in a single sample. Very small samples (e.g., $n=15$ ) are not likely to include a contaminated event, whereas very large samples (e.g., $n=500$ ) are much more likely to include one or more contaminated events. Table 6 provides the probability values that no contaminated population event belongs to a single sample for both $1 \%$ and $5 \%$ contamination. The probability that no contaminated event belongs to a single sample with $1 \%$ moderate or severe contamination in the population is given by $(3958 / 3998)^{n}$, and the probability that no contaminated event belongs to a single sample with $5 \%$ moderate or severe contamination in the population is given by $(3958 / 4158)^{n}$ in Table 6 . For $1 \%$ moderate or severe contamination, the probability of selecting no contaminated events from the population is greater than 0.50 for samples of size $n \leq 65$. For $5 \%$ moderate or severe contamination, the probability of selecting no contaminated events from the population never exceeds 0.50 . Given the well-known sensitivity of LSD regression to extreme events, it is not surprising that LSD regression yields optimistic levels of expected skill for larger samples that are more likely to contain one or more moderate or severely contaminated events. It should be noted in Table 5 that neither LSD nor LAD regression is able to accommodate $5 \%$ severe contamination.

The single sample estimate of shrinkage, $\mathrm{C} 4$, is higher for 6 predictors than for 10 predictors in Table 1 with LAD regression and $n \leq 160$ and with LSD regression and $n \leq 250$, in Table 2 with LAD regression and $n \leq$ 250 , and with LSD regression and $n \leq 40$. The same relationship holds for both LAD and LSD regression in Table 3 with $n \leq 40$ and in Tables 4 and 5 with $n \leq 25$. These results are consistent with the influence of contamination since when $n$ is small, the influence of additional noninformative predictors is mitigated because the probability of selecting a contaminated event in each sample is reduced. Clearly, regression models containing noninformative predictors should be avoided (Browne and $\mathrm{Cu}$ deck 1992).

The standard deviations of the $10000 \hat{\rho}$ values composing $\mathrm{C} 2, \mathrm{SD}(\hat{\rho} \mid \mathrm{C} 2)$, and the standard deviations of the 10000 drop-one $\hat{\rho}$ values composing C4, SD $(\hat{\rho} \mid \mathrm{C} 4)$, are given for each sample size $(n=15, \ldots, 500)$, case $(10$ and 6 predictors), and regression model (LAD and LSD) combination in Tables 7, 8, 9, 10, and 11, which correspond to the five contamination levels of Tables 1, 2, 3 , 4, and 5, respectively. In particular,

$$
\mathrm{SD}(\hat{\rho})=\left[\frac{1}{M-1} \sum_{i=1}^{M}\left(\hat{\rho}_{i}-\bar{\rho}\right)^{2}\right]^{1 / 2},
$$

where

$$
\bar{\rho}=\frac{1}{M} \sum_{i=1}^{M} \hat{\rho}_{i},
$$

$M=10000$ in this study, and $\bar{\rho}$ corresponds to either C2 or $\mathrm{C} 4$. The standard deviations are confined to $\operatorname{SD}(\hat{\rho} \mid \mathrm{C} 2)$ and $\operatorname{SD}(\hat{\rho} \mid \mathrm{C} 4)$ since the associated estimable single sample $\hat{\rho}$ values exist only for $\mathrm{C} 2$ and $\mathrm{C} 4$. For all five tables, $\mathrm{SD}(\hat{\rho} \mid \mathrm{C} 2)$ is smaller than $\mathrm{SD}(\hat{\rho} \mid \mathrm{C} 4)$ for small sample sizes. However, $\operatorname{SD}(\hat{\rho} \mid \mathrm{C} 2)$ and $\mathrm{SD}(\hat{\rho} \mid \mathrm{C} 4)$ become more similar to one another with increasing sample sizes. Also for all five tables, the $\operatorname{SD}(\hat{\rho} \mid \mathrm{C} 2)$ values are fairly similar for cases with 10 and 6 predictors; this also holds for the $\operatorname{SD}(\hat{\rho} \mid \mathrm{C} 4)$ values. The differences between LAD and LSD regression for both $\mathrm{SD}(\hat{\rho} \mid \mathrm{C} 2)$ and $\mathrm{SD}(\hat{\rho} \mid \mathrm{C} 4)$ are more complex. While $\mathrm{SD}(\hat{\rho} \mid \mathrm{C} 2)$ is smaller for LAD regression than for LSD regression with small sample sizes $(15,25$, and 40), the $\mathrm{SD}(\hat{\rho} \mid \mathrm{C} 2)$ and $\mathrm{SD}(\hat{\rho} \mid \mathrm{C} 4)$ values are larger (perhaps slightly) for LAD regression than for LSD regression in Table 7. In Tables 8 and $9, \mathrm{SD}(\hat{\rho} \mid \mathrm{C} 2)$ is smaller for $\mathrm{LAD}$ regression than for LSD regression whereas this observation holds for $\mathrm{SD}(\hat{\rho} \mid \mathrm{C} 4)$ only with large sample sizes (250 and 500). In Tables 10 and 11, except for $\operatorname{SD}(\hat{\rho} \mid \mathrm{C} 2)$ with small sample sizes $(15,25$, and 40), both $\operatorname{SD}(\hat{\rho} \mid \mathrm{C} 2)$ and $\operatorname{SD}(\hat{\rho} \mid \mathrm{C} 4)$ are larger for LAD regression than for LSD regression.

\section{Summary}

Mielke et al. (1996) investigated the effects of sample size, type of regression model, and noise-to-signal ratio on the degree of shrinkage in five populations containing varying amounts and degrees of data contamination. Shrinkage was measured as the ratio of the validation fit of a sample-based regression model to the retrospective fit of the same regression model where the validation fit was assessed on five independent samples from the same population. While the Mielke et al. (1996) index of shrinkage is both rigorous and comprehensive, it involves an additional five independent samples and thus is not useful in routine applications. In this paper a drop-one single-sample estimator of shrinkage is developed and evaluated on the same dataset used by Mielke et al. (1996). The drop-one single-sample estimator provides an accurate estimate of shrinkage for the five populations, both regression models, both cases, and all sample sizes, although the estimator is slightly conservative for very small sample sizes.

Finally, a caution is raised because the drop-one single-sample estimate of shrinkage is, in fact, an estimate of shrinkage. There is evidence that the drop-one method provides inflated estimates of validation fit for the LSD regression model when the population data is contaminated by extreme values, e.g., populations $1-4$ in Tables 1-4. In population 5 (Table 5) with $5 \%$ severe contamination, both the LSD and LAD regression models provide estimates of validation fit that are too high.

Acknowledgments. This study was supported by National Science Grant ATM-9417563.

\section{REFERENCES}

Badescu, V., 1993: Use of Willmott's index of agreement to the validation of meteorological models. Meteor. Mag., 122, 282-286. Barnston, A. G., and H. M. Van den Dool, 1993: A degeneracy in 
cross-validated skill in regression-based forecasts. J. Climate, $\mathbf{6}$, 963-977.

Browne, M. W., 1970: A critical evaluation of some reduced-rank regression procedures. Research Bulletin 70-21, Educational Testing Service, Princeton, NJ.

- 1975a: Predictive validity of a linear regression equation. $B r$. J. Math. Statist. Psychol., 28, 79-87.

— 1975 b: A comparison of single sample and cross-validation methods for estimating the mean squared error of prediction in multiple linear regression. Br. J. Math. Statist. Psychol., 28, 112 120.

—, and R. Cudeck, 1989: Single sample cross-validation indices for covariance structures. Mult. Behav. Res., 24, 445-455.

$\longrightarrow$, and - 1992: Alternative ways of assessing model fit. Sociol. Meth. Res., 21, 230-258.

Camstra, A., and A. Boomsma, 1992: Cross-validation in regression and covariance structure analysis. Soc. Meth. Res., 21, 89-115.

Copas, J. B., 1983: Regression, prediction, and shrinkage. J. Roy. Statist. Soc., 45B, 311-354.

Cotton, W. R., G. Thompson, and P. W. Mielke, 1994: Real-time mesoscale prediction on workstations. Bull. Amer. Meteor. Soc., 75, 349-362.

Efron, B., 1983: Estimating the error rate of a prediction rule: Improvement on cross-validation. J. Amer. Statist. Assoc., 78, 316331

Elsner, J. B., and C. P. Schmertmann, 1993: Improving extendedrange seasonal predictions of intense Atlantic hurricane activity. Wea. Forecasting, 8, 345-351.

- , and - 1994: Assessing forecast skill through cross-validation. Wea. Forecasting, 9, 619-624.

Geisser, S., 1975: The predictive sample reuse method with applications. J. Amer. Statist. Assoc., 70, 320-328.

Glick, N., 1978: Additive estimators for probabilities of correct classification. Pattern Recog., 10, 211-222.

Gray, W. M., C. W. Landsea, P. W. Mielke, and K. J. Berry, 1992: Predicting Atlantic seasonal hurricane activity 6-11 months in advance. Wea. Forecasting, 7, 440-455.

Hess, J. C., and J. B. Elsner, 1994: Extended-range hindcasts of tropical-origin Atlantic hurricane activity. Geophys. Res. Lett., 21, 365-368.

Hora, S. C., and J. B. Wilcox, 1982: Estimation of error rates in several-population discriminant analysis. J. Marketing Res., 19, $57-61$.

Horst, P., 1966: Psychological Measurement and Prediction. Wadsworth, $455 \mathrm{pp}$.

Huberty, C. J., J. M. Wisenbaker, and J. C. Smith, 1987: Assessing predictive accuracy in discriminant analysis. Mult. Behav. Res., 22, 307-329.

Kelly, F. P., T. H. Vonder Haar, and P. W. Mielke, 1989: Imagery randomized block analysis (IRBA) applied to the verification of cloud edge detectors. J. Atmos. Oceanic Technol., 6, 671-679.

Lachenbruch, P. A., 1967: An almost unbiased method of obtaining confidence intervals for the probability of misclassification in discriminant analysis. Biometrics, 23, 639-645.
—, and M. R. Mickey, 1968: Estimation of error rates in discriminant analysis. Technometrics, 10, 1-11.

Lee, T. J., R. A. Pielke, and P. W. Mielke, 1995: Modeling the clearsky surface energy budget during FIFE 1987. J. Geophys. Res., 100, 25 585-25 593 .

Livezey, R. E., A. G. Barnston, and B. K. Neumeister, 1990: Mixed analog/persistence prediction of seasonal mean temperatures for the USA. Int. J. Climatol., 10, 329-340.

MacCallum, R. C., M. Roznowski, C. M. Mar, and J. V. Reith, 1994: Alternative strategies for cross-validation of covariance structure models. Mult. Behav. Res., 29, 1-32.

Maltz, M. D., 1994: Deviating from the mean: The declining significance of significance. J. Res. Crime Delinq., 31, 434-463.

McCabe, G. J., and D. R. Legates, 1992: General-circulation model simulations of winter and summer sea-level pressures over North America. Int. J. Climatol., 12, 815-827.

Michaelsen, J., 1987: Cross-validation in statistical climate forecast models. J. Climate Appl. Meteor., 26, 1589-1600.

Mielke, P. W., K. J. Berry, C. W. Landsea, and W. M. Gray, 1996: Artificial skill and validation in meteorological forecasting. Wea. Forecasting, 11, 153-169.

Mosier, C. I., 1951: Symposium: The need and means of cross-validation, I. Problems and designs of cross-validation. Educ. Psych. Meas., 11, 5-11.

Mosteller, F., and J. W. Tukey, 1977: Data Analysis and Regression. Addison-Wesley, $586 \mathrm{pp}$.

Murphy, A. H., and R. L. Winkler, 1984: Probability forecasting in meteorology. J. Amer. Statist. Assoc., 79, 489-500.

Nicholls, N., 1985: Predictability of interannual variations of Australian seasonal tropical cyclone activity. Mon. Wea. Rev., 113, 1144-1149.

Picard, R. R., and R. D. Cook, 1984: Cross-validation of regression models. J. Amer. Statist. Assoc., 79, 575-583.

— , and K. N. Berk, 1990: Data splitting. Amer. Statist., 44, 140147.

Snee, R. D., 1977: Validation of regression models: Methods and examples. Technometrics, 19, 415-428.

Stone, M., 1974: Cross-validatory choice and assessment of statistical predictions. J. Roy. Statist. Soc., 36B, 111-147.

- 1978: Cross-validation: A review. Math. Operationsforsch. Statist., Ser. Statistics, 9, 127-139.

Subrahmanyam, M., 1972: A property of simple least squares estimates. Sankhya, 34B, 355-356.

Toussaint, G. T., 1974: Bibliography on estimation of missclassification. IEEE Trans. Inf. Theory, 20, 472-479.

Tucker, D. F., P. W. Mielke, and E. R. Reiter, 1989: The verification of numerical models with multivariate randomized block permutation procedures. Meteor. Atmos. Phys., 40, 181-188.

Watterson, I. G., 1996: Nondimensional measures of climate model performance. Int. J. Climatol., 16, 379-391.

Willmott, C. J., 1982: Some comments on the evaluation of model performance. Bull. Amer. Meteor. Soc., 63, 1309-1313.

— , S. G. Ackleson, R. E. Davis, J. J. Feddema, K. M. Klink, D. R. Legates, J. O'Donnell, and C. M. Rowe, 1985: Statistics for the evaluation and comparison of models. J. Geophys. Res., 90, 8995-9005. 